\title{
A Externalização de Atividades: Fundamentos e Experiências no Setor de Autopeças Gaúcho
}

\author{
Ivan Antônio Pinheiro
}

\begin{abstract}
RESUMO
Inicialmente, este trabalho identifica, na literatura, as principais vertentes do pensamento teórico que fundamentam as decisões de subcontratação e terceirização para, logo a seguir, a partir de elementos de uma pesquisa em andamento no Rio Grande do Sul, verificar em que medida as experiências vêm confirmando as proposições téoricas. Além dos dados da pesquisa, o trabalho utiliza matérias publicadas em revistas de negócios e periódicos de cunho acadêmico. $\mathrm{O}$ autor defende o argumento de que admitir a subcontração e a terceirização como uma tendência a ser seguida por (quase) todas as empresas, independentemente do porte e/ou setor por exemplo, é precipitada, pois há circunstâncias em que a subcontratação pode aumentar os custos da empresa, comprometer a qualidade, trazer incerteza aos prazos de desenvolvimento e entrega, e expor a sua tecnologia, entre outras características relacionadas à sua competitividade.
\end{abstract}

Palavras-chaves: terceirização; subcontratação; tecnologia; competitividade; indústria automotiva.

\begin{abstract}
This paper discusses the main theoretic arguments that sustain the subcontracting decision by firms. It also reports a fieldwork conducted in Rio Grande do Sul, Brazil, that tries to verify how such theoretical concepts work in practice. Secondary data were collected on business magazines and scientific journals. These data reinforce the author's argument that subcontracting should not be considered as a general tendency, because in some cases it may be unprofitable, raising costs, reducing quality, increasing uncertainty concerning products and delivery schedules. Moreover, when the technology is the advantage of a company, subcontracting may reduce its competitive power.
\end{abstract}

Key words: outsourcing; subcontracting; technology; competitivity; automotive industry. 


\section{INTRODUÇĀO}

Subcontratação ou terceirização? A começar pela própria denominação há controvérsia nos textos técnicos e na imprensa especializada. Não raro, se utilizam do termo subcontratação, ainda que o exemplo mencionado seja mais adequado à terceirização e/ou vice-versa; há, ainda, situações em que as expressões são empregadas como se fossem sinônimos.

Um dos critérios mais freqüentemente utilizados para distinguir a terceirização da subcontratação é a separação entre as atividades-meio (de apoio) e as atividades finalísticas; entretanto a dificuldade persiste pois, para terceirizar ou subcontratar, requer-se uma prévia definição do que seja a atividade finalística da empresa, cabendo às demais, a denominação de atividade-meio.

Simples numa primeira análise, a diferenciação adquire contornos não muito claros, quando se verifica que se há tendências que apontam para uma atuação focalizada (nichos de mercado, especialização em produtos/processos etc), contribuindo para distinguir as atividades-fim daquelas de apoio, há também movimentos contrários. Amparadas nas tecnologias de base microinformática (equipamentos miniaturizados, de baixo custo e grande capacidade de armazenagem, velocidade de acesso, recuperação, processamento e análise de dados) muitas empresas têm reposicionado a importância relativa das suas funções internas, por exemplo nas áreas de informações, de pesquisa e inovação tecnológica, que têm crescido em importância. A integração crescente entre os diversos subsistemas organizacionais também contribui para diminuir a clareza da distinção entre as atividades finalísticas versus de apoio; assim, o que antes era apoio, pela interdependência, torna-se crítico e adquire a importância do essencial. Já outras empresas, por motivos diversos, têm re-internalizado atividades (meio e/ou fim) antes adquiridas externamente e, por este motivo, também redefinem o que seja meio e/ou fim, por exemplo as empresas que antes forneciam componentes, aumentando o valor agregado dos seus produtos, passam a oferecer (fazer) sistemas ou subsistemas mais complexos.

Se, pelas razões expostas, entre outras, na literatura ainda não há solução definitiva acerca das diferenças entre a terceirização e a subcontratação, no mundo real a prática de externalizar atividades (denominação que supera as dificuldades mencionadas) difunde-se entre as organizações como uma alavanca para a produtividade e competitividade, justificando, assim, a continuidade dos esforços para obter melhor entendimento deste fenômeno. Mais do que diferenças semânticas, expressões a 
exemplo de fornecedor, terceiro, subcontratado, faccionista e parceiro, entre outras, correspondem a relações interfirmas e estruturas organizacionais diferenciadas, nos aspectos estáticos e dinâmicos, cujo entendimento das especificidades se revela indispensável a qualquer projeto que tem por objetivo a excelência gerencial.

Para reafirmar a amplitude do tema, cabe mencionar a citação de Peter Senge: "Só não podemos terceirizar nossa própria alma". Destarte, este trabalho tem estes objetivos:

- apresentar alguns fundamentos que justificam as iniciativas de Externalização de Atividades (EA) por parte das organizações;

- verificar como os fundamentos e os resultados destas iniciativas foram relatados por algumas organizações do setor de autopeças, localizadas no Estado do Rio Grande do Sul; por fim,

- demonstrar que, embora algumas publicações citem as práticas de EA como tendência inexorável e universal, sem distinções de atividade, há situações em que esta não se aplica.

Tomando-se como apoio as referências encontradas na literatura, de que se procurou extrair o que se poderia denominar o essencial da fundamentação teórica, $\mathrm{o}$ trabalho se completa com exemplos extraídos de uma pesquisa ${ }^{(1)}$, cuja equipe o autor integrou. Associada às iniciativas de EA, a literatura enfatiza o surgimento de novo tipo de relacionamento interfirmas, pautado na cooperação (parceria), razão pela qual este trabalho também apresenta alguns aspectos que sobre este tema emergiram na pesquisa.

\section{Terceirizaçāo ou Subcontratação?}

Brasil (1993, p. 7-8, grifo não existente no original) define a terceirização "[...]como um processo de transferência, dentro da firma (empresa-origem), de funções que podem ser executadas por outras empresas (empresa-destino). Essas funções incluem atividades de apoio ou aquelas diretamente relacionadas com o processo de produção da firma".

Dutra, Castilhos e Borba (1993, p. 4, grifo não existente no original) definem a terceirização como o ato de "transferir para terceiros atividades secundárias e concentrar-se cada vez mais na sua atividade principal, a fim de tornar-se mais competitivo". Adiante, acrescentam: 
“[...] é atribuir a terceiros serviços e afazeres que podem perfeitamente ser executados longe das vistas e até mesmo do controle do efetivo tomador principal desses mesmos serviços e afazeres. É a transferência pura e simples a terceiros, de atividades que possam ser tidas como 'atividade-meio', ou seja, aquelas que apenas concorrem para a elaboração final do produto, ou do serviço, como alternativa válida de flexibilidade empresarial”.

Na mesma linha, o editor dos Cadernos CEDOPE (1993, p. 3) destaca na Apresentação os temas tratados nessa edição: "a terceirização e a racionalização das 'atividades-meio' em benefício das 'atividades-fim' [...]'.

Henkin (1995, p. 22) reserva "o termo subcontratação industrial para indicar a relação em que uma empresa (subcontratada) fornece regularmente peças, componentes e serviços ligados diretamente ao processo de produção de outra empresa (subcontratante)".

Kruglianskas (1996, p. 8) menciona que "no Brasil, com a abertura para o mercado externo, as grandes empresas passaram a terceirizar boa parte de seu processo produtivo".

Abreu e Sorj (1994, p. 64, grifo não existente no original) sintetizam a controvérsia que se verifica na literatura:

“Os processos de subcontratação presentes hoje nas sociedades industriais podem assumir duas modalidades [...] A primeira, de desenvolvimento mais recente, envolve uma terceirização [onde] As inovações tecnológicas e de gestão da produção obtidas ao nível da empresa subcontratante são transferidas para as empresas subcontratadas [...] O segundo caso que pode ser chamado de 'terceirização por contingência' significa a externalização da produção como mecanismo de redução de custos de produção".

Estes exemplos são suficientes para demonstrar a dificuldade encontrada na literatura quando se procura estabelecer claramente uma distinção entre as práticas de terceirização versus as de subcontratação. Assim:

- para Brasil (1993) a terceirização abrange tanto as atividades-meio quanto as atividades-fim;

- já para Dutra, Castilhos e Borba (1993) a terceirização restringe-se tão somente as atividades-meio, por eles denominadas como secundárias; 
- Henkin (1995) reserva a expressão subcontratação para as atividades relacionadas à razão de ser da empresa, cabendo à terceirização aquelas que, por outros, são denominadas como sendo atividades-meio, secundárias;

- Abreu e Sorj (1994), por fim, ao utilizarem de forma intercalada as expressões, emprestam-lhes o mesmo significado.

Dentre os diversos, e por vezes conflitantes enfoques, o de Henkin (1995) parece reunir o maior número de adeptos. Assim, o verbo terceirizar denotaria as iniciativas de externalização das atividades de apoio, sobretudo as administrativas: as de limpeza, de segurança patrimonial, refeições etc. Entretanto, mais recentemente, outras atividades têm sido objeto de terceirização: seleção, treinamento e desenvolvimento de recursos humanos, pesquisa de mercado, publicidade, vendas, contabilidade e as atividades de informática, entre outras. Por outro lado, a externalização das tarefas diretamente relacionadas ao objeto social da empresa, ou seja, às suas atividades finalísticas, seria designada por subcontratação. Em vista dos argumentos já relacionados na introdução, esta definição não supera a dificuldade da segregação entre as atividades-meio e as atividades-fim. À guisa de exemplo, como denominar as atividades de manutenção (típicas de apoio às atividades finalísticas) realizadas por equipes externas, ou ainda, a contratação das atividades de P\&D\&E (finalísticas ou de apoio), muitas vezes críticas para o sucesso a longo prazo das empresas?

Se persiste dúvida nos textos acadêmicos quanto à diferenciação existente entre terceirização versus subcontratação, no mercado, que se utiliza de outro critério para a delimitação, esta diferença adquire contornos mais evidentes, conforme adiante será visto.

À margem desta controvérsia acadêmica, neste trabalho utiliza-se a expressão externalização de atividades para designar todas as iniciativas que signifiquem a transferência parcial ou total de tarefas, antes realizadas por uma empresa (empresa-origem, empresa-mãe, subcontratante etc), para outras empresas (empresadestino, subcontratada etc). Independentemente da taxonomia utilizada, embora esta seja mais do que uma questão apenas semântica, conforme já mencionado, importa destacar que a EA surge no âmbito das estratégias voltadas para a flexibilização, focalização de atividades e/ou para o aumento da produtividade e competitividade através da redução de custos.

Na seqüência, procurar-se-á demonstrar que, na raiz das iniciativas para a EA, encontra-se a própria limitação física e cognitiva dos seres humanos para atingir os seus objetivos, sendo a empresa somente mais um espaço em que esta limitação se manifesta. O desenvolvimento tecnológico aplicado à produção pode redimensionar esta questão. 


\section{Os Fundamentos Teóricos para a Externalização das Atividades}

\section{A Teoria da Racionalidade Limitada}

No discurso proferido na Academia Sueca, por ocasião do recebimento do Prêmio Nobel, Simon (1979) passa em revista as diferentes abordagens relativas ao processo de tomada de decisão, bem como avalia a sua contribuição ao tema. Inicia com a abordagem clássica ${ }^{(2)}$, cuja proposta de racionalidade das decisões (a decisão ótima, que assegura a maior eficiência) depende apenas da identificação do conjunto básico das informações necessárias à análise e entendimento do ambiente, ou seja, das variáveis que possibilitem diagnosticar, prever e simular o comportamento do ambiente, mediante as relações identificadas no sistema. Citando pesquisas, o autor demonstra que a racionalidade do processo decisório sob este ponto de vista é um mito, pois contraria os fatos, não havendo elementos que permitam a sua confirmação. Posicionamento análogo é defendido por Lindblom (1959) e Motta (1995), que exemplifica, entre outros, com o trabalho de Peters e Waterman (1983).

Simon (1979) avança na sua análise, considerando os modelos descritivos e normativos; mas conclui que também não correspondem à realidade dos fatos.

As dificuldades também enfrentadas pelos modelos comportamentais levam Simon (1979) à formulação da sua própria teoria, a da racionalidade limitada; na sua opinião, são muitos os fatores que contribuem para limitar o alcance da racionalidade: a existência e a dimensão do conjunto de informações disponíveis, a capacidade de processamento e análise destas informações, o custo (tempo $\mathrm{x}$ valor) da sua obtenção e até mesmo as expectativas do decisor, isto é, o seu conceito de ótimo, definido e influenciado por suas crenças, seus valores, as motivações e atitudes oportunistas, as heurísticas individuais, o conhecimento acumulado, as experiências etc. Assim, na prática, ao invés de decisões ótimas, as pessoas, bem como as empresas atuam (decidem, operam, avaliam, reconsideram etc) com soluções satisfacientes, isto é, satisfatoriamente eficientes, ou ainda, limitadamente eficientes à luz do contexto.

Nesta linha de entendimento, surge um dos fundamentos para as práticas de EA por parte das organizações: à semelhança das pessoas, limitadas na sua racionalidade, isto é, na identificação do conjunto ótimo de soluções, as organizações necessitariam externalizar as atividades (meio e/ou fim), para assegurar a eficiência global. Para superar os seus limites internos da eficiência, as organizações deveriam identificar outras organizações que reunissem informações, tecnologia, experiência, especialização, custo etc, que correspondessem à melhor 
solução dos problemas que excedessem a sua capacidade interna de otimização. A externalização das atividades seria decorrência da busca incessante pela maior eficiência, limitada pelas capacidades individuais, no primeiro nível, e organizacionais já em estágio de agregação.

À guisa de ilustração, Brasil (1993, p. 7), enquanto resgata as críticas à visão neoclássica, aponta as razões que levam uma empresa à EA: “[...] outro fator que justifica a inexistência do best way refere-se às limitações cognitivas inerentes aos tomadores de decisão". Ainda na mesma página acrescenta que o que "[...] ocorre na realidade é uma incongruência entre a idealização estratégica - que intenciona ser racional-compreensiva - e a implementação - que freqüentemente é do tipo satisfacing ou incremental".

\section{A Teoria dos Custos de Transação}

A teoria dos custos de transação (TCT) tem sido apontada por alguns autores, a exemplo de Henkin (1995) e Cunha (1996), como um dos fundamentos para a EA. Em vista das contribuições aportadas por vários autores, a TCT é hoje também encontrada na literatura sob outras denominações, a exemplo da teoria contratual e teoria da agência (da firma) - distinguir as contribuições, que justificam as denominações, foge ao escopo deste trabalho. O livro The Nature of the Firm - Origins, Evolution, and Development, editado por Williamson e Winter (1993), reúne os principais autores e textos desta abordagem, tais como Coase, Rosen, e o próprio Williamson, entre outros.

De acordo com Zylberstajn (1996, p. 1), embora diferentes, as denominações constituem enfoques ligeiramente diferenciados "[...] para o entendimento dos contratos just-in-time, desenvolvimento de fornecedores, alianças estratégicas, reorganização da estrutura produtiva com base em contratos terceirizados, contratos de distribuição, entre outros".

Enquanto Adam Smith identifica na mão invisível do mercado o instrumento eficiente para a alocação dos recursos econômicos, reduzindo a importância da atuação gerencial, Coase (apud Henkin, 1995, p. 5) propõe que a eficiência alocatícia resulte do efeito combinado entre o mecanismo de preços (definido pelo mercado) e o planejamento e decisões gerenciais, sustentando "[...] que a coordenação pelo mercado e a coordenação pela firma são claramente métodos alternativos de coordenação da produção". O autor resgata a importância da decisão gerencial para a definição do nível de eficiência da firma que, até então, parecia conduzida tão somente pelas forças do mercado. Na mesma linha, Carleial $(1996$, p. 3) também destaca que Dosi et al. (1988) e Freeman et al. (1995) "discordam de que os sinais fornecidos pelo comportamento dos preços sejam suficientes para explicar o comportamento das firmas". 
Cunha (1996, p. 4) identifica as circunstâncias em que as decisões devem ser reguladas pelo mercado e quando devem ser submetidas ao escrutínio gerencial:

"A teoria dos custos de transação sustenta que as trocas únicas ou nãorepetitivas, que não exigem investimentos específicos para serem realizadas, devem ocorrer em 'mercados', onde são realizadas transações mercantis simples, mas as transações recorrentes, que envolvem incerteza sobre seus resultados e que requerem investimentos específicos, devem ocorrer, no limite, em 'hierarquias', ou melhor, em formas altamente centralizadas e hierarquizadas de organização coorporativa. Nesse sentido, as transações se movem de 'mercados' a 'hierarquias' com o acirramento da freqüência, da incerteza e da 'especificidade de ativos' relacionadas às transações".

Henkin (1995, p. 7) enumera os custos de transação identificados por Coase:

“a) o custo de descobrir quais são os preços relevantes para se estabelecer determinada escolha;

b) os custos de negociar e concluir um contrato separado para cada transação que ocorre no mercado [...];

c) as dificuldades que o comprador encontra para exigir do ofertante determinadas especificações no suprimento de bens ou serviços, ao longo de um contrato de longo prazo, quando contratos de curto prazo são insatisfatórios $[\ldots] "$.

Portanto é do confronto (avaliação) entre os custos de transações, assim definidos, e os do mercado (dados tão somente pelo preço), que será decidida a internalização ou externalização das atividades, sendo "função do 'entrepreneur' coordenar tais transações de tal modo que seu custo seja sempre menor, caso contrário será possível tornar a realizar tais transações no mercado" (Henkin, 1995, p. 7). E conclui que "desta forma, a subcontratação industrial, definida como um modo (ou parte de um modo) de organizar um determinado processo de produção, deve ser explicada à luz da teoria dos custos de transação" (Henkin, 1995, p. 8).

Em que pese a sua completa estruturação para explicar o relacionamento entre setores produtivos e entre as empresas que integram uma mesma cadeia produtiva, a teoria dos custos de transação é vista por Simon (1979) como um desmembramento da racionalidade limitada, fato também assinalado por Williamson (1991). 


\section{A Focalização na Core Competence}

A minimização do grau de risco da atividade empresarial foi, por muito tempo, uma estratégia recomendada e, o instrumento, a constituição e a administração de portfólios, enfoque adaptado da teoria de investimentos. À semelhança dos administradores financeiros, que deveriam diluir os recursos em ativos diferenciados (renda fixa, variável, curto, médio e longo prazo, alto rendimento/risco, baixo rendimento/risco etc), os $\mathrm{CEO}^{(3)}$ deveriam fazer investimentos em mercados (regiões, setores, atividades etc) que, sob crise da recessão apresentassem rendimentos compensatórios, isto é, se uma atividade se apresentasse depressiva, a outra deveria apresentar rendimentos positivos, reduzindo ou mesmo eliminando o risco de prejuízo total. A hegemonia deste ponto de vista favoreceu o surgimento de conglomerados empresariais com interesses corporativos distribuídos entre diversos setores, indo desde a agroindústria até a microeletrônica, incluindo a administração da publicidade e dos núcleos de pesquisa e desenvolvimento dos setores correlatos.

Se por um lado essa estratégia trouxe contribuições para a minimização dos riscos, por outro também apresentou disfunções, levando muitas empresas a se desviarem da atividade principal, aquela que deu origem à sua existência e sobre a qual, por algum momento, reuniram um diferencial competitivo (Corrêa e Gianesi, 1993). Divididas entre várias áreas de negócios, individualmente cada vez mais complexos, as gestões tornaram-se conservadoras e distanciaram-se do seu objetivo principal - a maximização dos recursos/investimentos do acionista - abrindo espaço para o surgimento de novas, ágeis e eficientes empresas inovadoras, com personalidade própria no mercado, em vista da sua identificação com produtos e/ ou serviços.

Mais recentemente, alguns autores (Hamel e Prahalad, 1995) têm apontado as práticas de EA como a alternativa, tanto para sobreviver quanto para vencer num mercado que apresenta mudanças constantes e velozes, portanto caracterizado pela instabilidade. Neste ambiente, as empresas para serem bem sucedidas devem ser flexíveis, isto é, capazes de responder, sem prejuízo da qualidade e do prazo de entrega, a todas as variações requeridas pelo mercado: de volume, de mix, de distribuição geográfica, de inovação etc. Para ser flexível e eficiente, a empresa deve atuar sobre a sua competência principal, a sua capacitação-chave, alocando todos os esforços (ativos, inteligência, estratégias, alianças, pesquisa e desenvolvimento etc), isto é, focalizar a sua atividade, adquirindo identidade bem definida, tanto interna, junto ao seu quadro de pessoal, quanto externamente, para os clientes, fornecedores e comunidade em geral; assim obtém a sinergia indispensável ao êxito. As demais atividades, não integrantes da sua core competence, devem ser 
externalizadas para as empresas cuja razão de ser seja a busca da excelência sobre tais competências.

Contrariamente, Ford identificou na verticalização, a maneira de superar as incertezas e os custos de coordenação entre os diversos agentes do mercado: fornecedores, distribuidores etc. Construiu, assim, o seu império. Entretanto, mais tarde, não resistiu à estrutura divisional, mais focalizada, da General Motors.

Embora a falta de focalização venha sendo, por muitos, apontada como a causa da desagregação e ineficiência e falência dos grandes grupos, cabe lembrar que a excessiva centralização do processo decisório e suas conseqüências, típica mas não exclusiva das grandes corporações, parece ter tido o maior peso no destino destas empresas.

A incorporação das tecnologias de base microeletrônica, a facilidade e a velocidade em obter e processar informações, a emergência dos mercados de nichos são, entre outras, características que predominam neste final de século e que requerem uma agilidade de gestão (análise, decisão, execução, acompanhamento e avaliação), que se tem mostrado incompatível com as tradicionais estruturas conservadoras, centralizadas e lentas, que emergiram ao amparo da administração dos portfólios. Por outro lado, criam também, novas possibilidades para estas estruturas, agora revisionadas.

\section{As Cadeias Produtivas}

Até a década de sessenta predominavam na literatura os estudos que identificavam a organização como o espaço onde deveriam verificar-se as principais ações gerenciais, com vistas ao aprimoramento da eficiência. Embora fossem reconhecidas as vantagens da divisão técnica do trabalho inter-organizacional, admitia-se implicitamente que as ineficiências externas dos fornecedores, do poder público etc, poderiam ser compensadas com os esforços e as competências internas da organização. As iniciativas de gestão priorizavam as ações sob controle direto das organizações; o exemplo de Ford, acima citado, é ilustrativo. A crise econômica mundial, que atingiu diversos países, com diferentes graus de intensidade, no final dos anos sessenta/início dos anos setenta trouxe também mudanças na retórica da eficiência, vista desde então como o resultado de uma ação, bem e intencionalmente articulada entre os diversos atores econômicos ou, mais objetivamente do ponto de vista da gestão organizacional, daqueles agentes que diretamente ou indiretamente pudessem afetar o desempenho de toda a cadeia produti$\mathrm{va}^{(4)}$ de interesse da empresa. Sob este novo enfoque, a literatura aponta para duas linhas de pesquisas, que buscam explicar o sucesso econômico, a partir da noção difundida como eficiência coletiva: (1) a da experiência japonesa e, (2) a 
dos distritos industriais localizados; ambas são analisadas a seguir em seus aspectos históricos e elementos fundamentais.

\section{A Trajetória Japonesa}

Enquanto as economias ocidentais enfrentavam sérias dificuldades para superar a crise econômica que sucedeu ao litígio árabe-israelense, quando o petróleo foi utilizado como arma política, o Japão, carente de recursos naturais, apresentava desempenho ímpar, expresso em índices de produtividade até então inexistentes nas economias ocidentais. Superadas as primeiras avaliações ocidentais, que apontavam para as práticas de dumping e de protecionismo governamental como as responsáveis pelo vigor econômico japonês, houve o reconhecimento de que a maior contribuição para o aumento da produtividade/competitividade residia no elevado estágio da tecnologia gerencial, atingido na seqüência de um esforço contínuo, iniciado na fase da reconstrução pós-guerra (Pinheiro, 1995).

As técnicas ${ }^{(5)}$ relacionadas à gerência voltada para a qualidade total (Ishikawa, 1993), em paralelo àquelas ${ }^{(6)}$ desenvolvidas na Toyota Motor Co. (Monden, 1984; Ohno, 1988; Shingo, 1996), compunham um sistema (TQC/JIT) de elevada sinergia, alavancando os recursos através do envolvimento e do comprometimento de toda a empresa: da produção ao marketing, integrando também as áreas responsáveis pelas vendas, projetos, recursos humanos e pesquisas, entre outras. Os experimentos de Ohno (1988) e Ishikawa (1993) inauguraram nova era, inicialmente percebida e aplicada no campo da administração da produção, posteriormente impactando toda a organização.

À dimensão técnica outros aspectos devem ser adicionados, a exemplo das novas relações sindicais instituídas no pós-guerra (Womack et al., 1992). Xavier (1983, p. 34-35), enquanto chama a atenção para a contribuição dos aspectos históricos (Restauração Meiji após o Período Tokugawa), cultural (vida cooperativa, parcimoniosa etc) e religiosa (educação com base nos princípios dos xintoísmo e do budismo), destaca também o surgimento, antes da Primeira Guerra Mundial, dos,

"conglomerados empresariais que agrupavam e formavam uma sociedade de capital participado: os grupos zaibatsu [...] desempenhariam, a partir de então, papel definitivo e provocariam mudanças básicas na estrutura social, política e econômica do Japão. Eles prosperariam muito mais do que as empresas ou grupos não-zaibatsu. Três importantes fatores contribuíram para o sucesso dos grupos zaibatsu: 1) acesso fácil ao pleno capital; 2) facilidade em obter matéria-prima que lhes era vital; e, 3) disponibilidade da melhor e mais capaz mão-de-obra gerencial". 
A importância dos grupos zaibatsu para a sociedade japonesa também pode ser avaliada a partir do relato de Womack et al. (1992, p. 192), que chamam a atenção para uma das principais medidas das forças de ocupação que sucederam à rendição: "os americanos eliminaram tais grupos firmemente organizados durante sua ocupação do Japão pós-Segunda Guerra Mundial”. Entretanto,

\begin{abstract}
"com a partida dos americanos, o zaibatsu cedeu lugar a nova forma de finanças industriais, o keiretsu. Cada keiretsu consiste em cerca de 20 grandes companhias, uma em cada setor industrial. Ao contrário dos zaibatsu, inexiste uma companhia holding no topo da organização. Tampouco formam as companhias uma unidade legal. Na verdade mantêm-se unidas por uma estrutura de patrimônio de entrelaçamento mútuo - cada companhia possui parte do patrimônio líquido das demais, num padrão circular - e com um sentimento de interesse recíproco" (Womack et al., 1992, p.193).
\end{abstract}

No âmbito deste trabalho importa destacar a importância das estruturas corporativas japonesas para o surgimento e o aperfeiçoamento de um tipo de relacionamento entre os clientes e os seus fornecedores, sejam clientes e consumidores finais ou intermediários, dispostos ao longo da cadeia de produção, ainda pouco difundido na economia ocidental: a parceria. Ao favorecer o fluxo de recursos (matéria-prima, recursos humanos, capital, tecnologia etc) e informações (planejamento de produção, projetos, produtos, investimentos, idéias etc) entre os membros do grupo zaibatsu/keiretsu (acionistas recíprocos), a parceria representa uma significativa vantagem competitiva:

- promove a eficiência alocatícia através da distribuição dos recursos entre as organizações-membros que, por causa das alterações conjunturais, atuam nos setores mais dinâmicos e rentáveis;

· permite que cada organização-membro atue de forma focalizada;

- atua como amortecedor de crises, aproximando-se, sob este aspecto, da administração de portfólios; e,

- elimina ou reduz significativamente os mecanismos e os custos de controle contra a incerteza, por exemplo, e coordena os integrantes da cadeia produtiva, aproximando-se, sob este aspecto, da teoria dos custos de transação.

Cumpre enfatizar que as participações cruzadas de capital, ao gerarem interesses recíprocos e interdependência entre os membros corporativos, facilitam a externalização das atividades, uma vez que inexiste o clima de desconfiança, que limita o estreitamento das relações clientes/fornecedores no mundo ocidental e, 
segundo alguns autores, constitui uma das principais causas dos fracassos na implantação dos programas de gestão da qualidade total e dos sistemas de suprimento just-in-time (TQC/JIT).

\section{Os Distritos Industriais Localizados (DIL)}

Pyke e Sengenberger (1990), ao analisarem os desempenhos apresentados por alguns países e/ou unidades geo-econômicas, também identificaram a existência de outras ilhas de excelência: os Distritos Industriais (DI) que, em meio a recessão dos anos setenta/oitenta, conseguiram manter vigor econômico e apresentar crescimento.

Um dos primeiros DI identificados foi o da Terceira Itália, havendo, entretanto, estudos que apontam para a existência de outros, localizados na França, na Alemanha (Courlet, 1993) e Peru (Basay, 1996). Na experiência italiana, o que mais chamou a atenção dos pesquisadores não foi o desempenho econômico, mas a existência de uma forma de organização do sistema produtivo em torno do trabalho e das relações de emprego, que se distingue de outros modelos, a exemplo do fordismo, predominante nas grandes indústrias ocidentais, e do ohnismo, surgido no Japão, conforme visto anteriormente. Embora não haja unanimidade e devam ser observadas as especificidades regionais e culturais, as opiniões são convergentes em torno dos principais elementos que caracterizam os DI:

- a existência de uma cadeia produtiva geograficamente bem localizada;

- predomínio de micros, pequenas e médias empresas, freqüentemente familiares, que se especializam nas diversas etapas da produção e do beneficiamento de um produto final homogêneo e voltado para o consumidor final;

- predomínio da competição entre as empresas que desempenham a mesma atividade e da cooperação entre as firmas situadas em níveis distintos da cadeia produtiva;

- os ganhos de escala se verificam na cadeia produtiva e não no nível das unidades;

- a capacidade de inovação e adaptação às mudanças resulta, em parte, da mobilidade da mão-de-obra, transferindo o saber fazer, característica que integra um conjunto maior denominado de especialização flexível.

Um dos aspectos mais notáveis dos DI é o fato de que as empresas nele estabelecidas se beneficiam das externalidades positivas por ele geradas, isto é, à medida que aumenta a aglomeração localizada de empresas voltadas para a ativi- 
dade principal da cadeia produtiva, outras empresas de apoio buscam, por esta razão, estabelecer-se na sua área de influência, a exemplo de bancos, agências de viagens, escolas, distribuidores/revendedores, transportadoras, agentes de comércio internacional, entre outras atividades especializadas, todas orbitando em torno do centro de gravidade, definido pela atividade principal da cadeia produtiva. Um dos primeiros a relatar este aspecto foi o economista A. Marshall; daí, alguns DI se fazerem acompanhar, na literatura, do adjetivo marshalliano ou ainda, sob a denominação de Distritos Industriais Localizados (DIL), por razões consideradas a seguir.

Neste ambiente, a eficiência não resulta das iniciativas isoladas das empresas, mas do exercício aperfeiçoado de práticas coletivas, pela freqüência com que as empresas transferem entre si atividades predominantemente finalísticas. A repetição continuada de transferências entre as mesmas firmas, a cooperação (fluxo intenso e bilateral de informações, máquinas e equipamentos etc) e a informalidade são aspectos que se destacam e chegam, em muitos casos, a caracterizar efetivas parcerias entre empresas: assim, tornam-se ágeis e flexíveis, condições que, simultaneamente, lhes conferem produtividade/competitividade individual, assim como à cadeia produtiva que integram.

Brusco (1990), analisando a gênese dos DI, também alerta que não existe unanimidade entre os pesquisadores para distinguir dois tipos de distritos industriais: os que não contam e os que contam com a interferência ou apoio governamental. Embora semelhantes nas características básicas, este último já corresponde a uma resposta dos DI à internacionalização econômica: o surgimento de entidades intermediárias e centralizadoras, necessárias para assegurar o desempenho competitivo de algumas atividades. Entre as características básicas o autor destaca:

- a homogeneidade entre os produtos das firmas que desempenham funções análogas na cadeia produtiva;

- $\mathrm{o}$ forte relacionamento interfirmas;

- a relativa eqüidade salarial no distrito industrial;

- predomínio de produtos custom-made (a pedido, à hora e a custo);

- existência de elevada produtividade;

- emergência de empreendedores;

- a difusão de inovações, favorecida pela grande mobilidade da mão-de-obra e pela cooperação técnica interfirmas. 
Leite e Posthuma (1995, p. 5) chamam a atenção para o tipo de relacionamento interfirmas nos DI, "onde a relação entre as firmas cria um círculo virtuoso de sinergia entre inovação industrial e capacitação da mão-de-obra".

Embora surgidas em contextos sociais, históricos e culturais diferenciados, a trajetória japonesa e os distritos industriais italianos apresentam-se semelhantes em alguns aspectos (grande flexibilidade, ampla cooperação interfirmas, produtos custom-made, entre outros), porém, distintos em outros: enquanto o modelo japonês dispõe de mecanismos que estimulam a fixação da mão-de-obra na empresa, os distritos industriais da Terceira Itália caracterizam-se pela grande mobilidade dos recursos humanos e pelo surgimento de empreendedores.

O peso dos antecedentes sociopolíticos e culturais, entre outras dimensões históricas, distingue os DI. Acirra o debate quanto à sua transferibilidade ou reprodutibilidade e reforça a preferência pelo emprego da expressão Distritos Industriais Localizados. Pode-se, entretanto, afirmar que no que tange aos aspectos técnicos, há elementos das duas trajetórias que já foram reproduzidos, com êxito, em outros ambientes de tradição sócio-econômica e cultural distintas.

Diferenças à parte, no seio da crise iniciada nos anos setenta, as duas alternativas se mostraram promissoras perante os desafios da nova ordem econômica, em particular no que interessa a este trabalho: o estabelecimento de novo padrão de relacionamento interfirmas, visto como instrumento e estratégia para aumentar a competitividade, ou seja, capaz de conferir flexibilidade, redução continuada de custos/preços, difundir com rapidez as inovações e atender às necessidades dos nichos de mercados.

\section{As Contribuições dos Diversos Enfoques}

Em que pese este trabalho ter apresentado uma relação dos cinco mais freqüentes argumentos utilizados para justificar as iniciativas de externalização de atividades, na prática trata-se de enfoques complementares que, isoladamente, se revelam insuficientes para explicar a trajetória de longo prazo da maioria dos casos analisados. As empresas, tanto quando externalizam, quando reinternalizam algumas de suas atividades, enumeram argumentos que ora se apóiam na racionalidade limitada: externalizam, quando em fase de crescimento acelerado e desordenado; ora na teoria dos custos de transação: internalizam, se há riscos/ custos de continuidade de fornecimento de um item crítico; ora na focalização: atuam em áreas de acelerada atualização tecnológica. Por outro lado, estas três linhas de argumentação, seja para a internalização ou para a externalização, não colidem, conforme já destacado, com a trajetória das cadeias produtivas, havendo nestas, diversas características daquelas. À guisa de ilustração, enquanto os cus- 
tos mencionados por Henkin (1995) são utilizados como argumentos para algumas empresas internalizarem atividades, eles praticamente inexistem na trajetória japonesa, favorecendo portanto, a externalização. Já os distritos industriais na sua gênese foram fortemente impulsionados pelos ganhos que poderiam obter através das externalidades.

O crescente inter-relacionamento das economias, fenômeno que se tem difundido com o nome de globalização, a velocidade acelerada com que se verificam as mudanças tecnológicas, a redefinição dos papéis ou espaços de atuação dos Governos e Estados Nacionais são apenas alguns, entre os relevantes acontecimentos contemporâneos, que têm conduzido a uma redefinição de aspectos fundamentais relacionados à gestão, em particular, sobre como atingir níveis sempre crescentes de eficiência e eficácia. Neste contexto, o interesse pelas iniciativas de EA tem sido revigorado e reconsiderado, pois é consistente com a nova lógica ${ }^{(7)}$, onde o locus das ações organizacionais não se limita à unidade empresarial, mas se estende às cadeias produtivas, às economias locais, regionais ou à nacional, devendo ainda ser avaliadas as oportunidades e as ameaças criadas pela emergência dos blocos econômicos supranacionais.

A maior amplitude da abordagem trouxe e exige nova forma de relacionamento interfirmas, pautada na cooperação e confiança. A cooperação, como esclarece Carleial (1996, p. 2), pode ser determinada por vários fatores e estabelecida em diferentes níveis, conforme:

“i) a especificidade da indústria que se analisa; ii) o conteúdo tecnológico do item produzido pela subcontratada; iii) a dependência entre a subcontratada e subcontratante no que se refere a faturamento e mercado; iv) a natureza e volume dos fluxos de informação entre elas; v) as suas estruturas de mercado respectivas; vi) a especificidade de seus mercados (nacional, internacional, regional, local); vii) a existência de estimulação institucional para o aprimoramento da colaboração; [e] viii) a disponibilidade de excedentes populacionais (no caso dos subdesenvolvidos)".

A seguir serão apreciadas algumas iniciativas de EA verificadas em pesquisa de campo realizada numa amostra de empresas privadas que atuam no setor de autopeças e operam a partir das suas instalações fabris, localizadas no Estado do Rio Grande do Sul. Pretende-se ilustrar, através de exemplos ${ }^{(8)}$, que:

- tanto as práticas de EA quanto os níveis de cooperação identificados encontram amparo nas referências da literatura mencionada; e,

- se do ponto de vista ético, social e do processo administrativo as práticas 
de cooperação pessoal e organizacional se justificam e, em princípio, devem ser estimuladas pelos aspectos positivos que congregam, o mesmo nem sempre se poderá afirmar quando o prisma de análise considerar aspectos estratégicos da organização, por exemplo.

\section{Algumas Evidências Observadas no Campo}

A amostra pesquisada constitui-se de 17 empresas, cujos produtos/serviços, em sua maior parte, são destinados à cadeia de produção automobilística. Distribuídas em 2 grupos, empresas-mãe e empresas-fornecedoras, a amostra foi obtida por indicação do presidente do Sindicado das Indústrias de Autopeças (SINDIPEÇAS, regional RS), como representativa de diferentes trajetórias/experiências de subcontratatação e/ou terceirização; portanto à amostra não pode ser atribuída representatividade estatística sobre o setor de autopeças, constituindo antes um conjunto de casos ilustrativos de exceções ao que, aparentemente, se vem configurando como tendência generalizada: a externalização de atividades.

O primeiro grupo, de empresas-mãe, é constituído pelas maiores empresas, que fornecem e/ou estão em condições de atender diretamente as montadoras e que externalizam ou não algumas atividades para as empresas do segundo grupo, $o$ das empresas-fornecedoras. Das 10 empresas originalmente indicadas para participarem da pesquisa, 1 recusou-se a prestar informações e somente 3 externalizam atividades finalísticas. Entre as demais, ou já externalizaram ou estão em vias de externalizar as atividades de apoio; das que externalizam atividades finalísticas, todas também externalizaram as atividades de apoio.

A seguir será apresentado breve sumário acerca do histórico, do negócio, das características do processo produtivo, da tecnologia, entre outros aspectos das empresas-mãe, que contribuem para o melhor entendimento da postura que mantém em face das práticas relacionadas à externalização de atividades. Visando à preservação das suas identidades, as empresas serão identificadas através de letras e apenas o mínimo de informação individual, necessário à contextualização do tema abordado, será fornecido.

- Empresa A. Atua num setor de tecnologia madura de forjaria e metalurgia; seus produtos são feitos sob encomenda e $80 \%$ do seu faturamento vem do mercado nacional. Sua vantagem competitiva está na ferramentaria especializada, cujas peças são produzidas em casa, sob medida. Externaliza os processos mais específicos, que agregam valor aos produtos e os pedidos que, devido ao pequeno 
volume, não compensam os custos de preparação e operação internos. Tem restrições, por motivo de segurança patrimonial e qualidade, à externalização das atividades de apoio.

- Empresa B. No seu setor de atuação, utiliza tecnologia de ponta, restrita a poucas indústrias: a sinterização, metalurgia de metais em pó. O produto básico é padronizado e produzido em larga escala. Entretanto, dependendo da aplicação, admite variações de tipo e tamanho. Seu diferencial competitivo está na tecnologia básica, incorporada às máquinas e equipamentos importados, de grande valor, que requerem operadores especializados e que, nas primeiras fases do processo, definem a especificidade e características técnicas dos produtos. As demais atividades, de apoio ou finalísticas, a empresa tem procurado externalizar.

- Empresa C. Sua tecnologia básica é a sinterização, cujo know-how adquiriu da matriz no exterior, assim como os aperfeiçoamentos que vêm incorporando. Seu insumo principal é importado, o processo de produção é contínuo e os produtos, peças minúsculas e de precisão, adquirem suas características básicas nas fases iniciais do processo, sendo as demais, atividades típicas de acabamento. Concentra-se na principal etapa do processo produtivo, definida pela tecnologia, externalizando as demais, sobretudo, as de apoio.

- Empresa D. Utilizando tecnologia madura, distingue-se no mercado pela sua atuação gerencial que, apoiada em modernas instalações e equipamentos, a situam como uma empresa global: $25 \%$ do seu faturamento é proveniente de exportações diretas, enquanto o restante é vendido para empresas também exportadoras. A distância dos principais fornecedores e os problemas externos de qualidade limitam e fazem com que a EA seja parcial: utilizada nos processos experimentais, de pequenos volumes, para absorver as variações de mercado e/ ou aguardar a consolidação de alguma tendência, em especial, as tendências à expansão. Certificada na ISO 9.001, busca ampliar o número de fornecedores com qualidade assegurada com a troca de informações tecnológicas, às quais tem acesso atualizado por meio do parceiro internacional, e apoio gerencial em projetos de qualidade, organização e gestão da produção, entre outros.

- Empresa E. Produz peças padronizadas (elastômeros) em grande volume, e dirige seus produtos para o mercado nacional, sobretudo de reposição. Sua sustentação competitiva depende da contínua redução dos custos, sendo a EA uma dentre outras estratégias voltadas para este objetivo. Neste sentido tem identificado, treinado e investido na constituição de uma rede de empresas fornecedoras/prestadoras de serviços exclusivas, se possível.

- Empresa F. Produtora de material de fricção utilizado em ampla gama de atividades. A tecnologia original, de origem italiana, acumula aperfeiçoamentos de- 
senvolvidos nos últimos 20 anos (P\&D internos) e requer contínuos e vultosos investimentos. Reestruturações internas reduziram os custos e levaram a empresa a obter a certificação ISO 9.001. Entretanto é na sua tecnologia de produto/processo, resultado das experiências internas, que identifica a sua vantagem competitiva; daí a impossibilidade de externalizar as atividades produtivas, pois implicaria expor segredos industriais. Já as atividades de apoio encontram-se em acelerado ritmo de externalização.

- Empresa G. A fundição de ferrosos/não-ferrosos e a forja de peças sob encomenda constituem o negócio da empresa, que destina $75 \%$ das suas vendas ao mercado interno. As máquinas e equipamentos utilizados, pesados e de grande porte, bem como a natureza dos processos, com ruído e calor elevados, requerem instalações especificamente projetadas, circunstâncias que dificultam ou até impedem a externalização das atividades finalísticas; neste caso, um eventual contratado externo seria um concorrente. Excepcionalmente, externaliza processos experimentais, cuja escala laboratorial ou para testes de mercado não justifica os custos de preparação e operação internos. A disponibilização de tempo e recursos para aprimorar os processos internos, em parte, resulta da contratação dos serviços de apoio.

- Empresa H. Forjaria em pequena escala e usinagem de precisão, em pequenos lotes de grande variabilidade, constitui a sua atividade. $\mathrm{O}$ trabalho em pequenos lotes (custom made) requer elevada qualificação da mão-de-obra para reduzir/ eliminar perdas (custos), nas fases de projeto, de protótipos e testes, de preparo e processo, o que levou a empresa a desenvolver engenharia própria e investir em modernos equipamentos que lhe conferem vários graus de liberdade. Em 1994 obteve a certificação na norma ISO 9.001. Ao longo de sua história, a empresa mudou, por diversas vezes, tanto a sua carteira de clientes, quanto os tipos de produtos majoritariamente responsáveis pelo seu faturamento. Sua vantagem competiviva está na sua memória técnica e na flexibilidade, aspectos que, simultaneamente, lhe conferem agilidade no mercado e impedem que externalize as atividades industriais. Sua localização, isolada geograficamente, foi determinante para a trajetória de crescimento verticalizado, e ainda hoje dificulta a própria externalização das atividades de apoio.

- Empresa I. Fundição e metalurgia de grandes peças, a linha pesada do setor automobilístico, constituem o seu negócio. Seus equipamentos e processos, à semelhança do que se verificou para a empresa $\mathrm{G}$, também exigem instalações específicas. Não externaliza atividades relacionadas ao seu negócio, vendendo entretanto, produtos em bruto, sem as etapas de maior valor agregado. 


\section{Breves Consideraçōes sobre as Experiências}

As informações vistas acima permitem verificar o que se segue.

- A empresa $\mathrm{A}$, devido à especificidade da sua vantagem competitiva e à natureza dos seus equipamentos, não pode externalizar as atividades produtivas; neste caso, teria de valer-se de um concorrente, com evidentes riscos ao seu posicionamento no mercado. Ainda que externalizasse, pouca ou nenhuma colaboração poderia desenvolver com o contratado, eliminando a possibilidade de vir a tê-lo como parceiro, objetivo natural dos que buscam melhorar a eficiência através do melhor arranjo entre as competências internas e externas.

- As empresas B e C possuem a sua core competence na tecnologia incorporada às máquinas e equipamentos, que configuram os produtos logo nas fases iniciais do processo industrial. Sem máquinas similares, que só um concorrente de porte equivalente ou maior poderia obter, o processo não pode ser reproduzido. As demais fases, mais simples, são passíveis de externalização, podendo, por estreita colaboração com o contratado, levar a uma redução de custos e ampliação externa da sua capacidade produtiva.

- A empresa D, que produz e monta componentes, subsistemas, para diversas linhas automobilísticas, diferencia-se pela excelência dos processos internos, o que lhe confere qualidade, flexibilidade e agilidade. $\mathrm{O}$ acesso à tecnologia externa não chega a constituir diferencial: trata-se de conhecimento já disseminado. Assim, sua produtividade resulta do efeito combinado entre o virtuosismo interno e as melhores práticas externas. A empresa $\mathrm{E}$, em que pese algumas diferenças (não exporta e não possui um parceiro externo, por exemplo), apresenta trajetória de externalização de atividades que se assemelha à da $\mathrm{D}$.

- Focalizar os esforços sobre a engenharia, os processos internos, a pesquisa e o desenvolvimento próprios amplia o diferencial competitivo e preserva dentro de casa os segredos industriais da empresa F. Assim, ao externalizar as demais atividades, libera os recursos, focalizando-os sobre a sua atividade precípua.

- As empresas $\mathrm{G}$ e $\mathrm{H}$ apresentam especificidades de produtos/processos que impedem a EA, ou a restringem a algumas etapas da transformação industrial. A sustentação competitiva destas empresas resulta da melhoria contínua dos processos internos e da obtenção de melhores condições dos fornecedores. Portanto a externalização das atividades que não estejam diretamente relacionadas com a produção contribui para focalizar as competências e os recursos na atividade principal. 
- Até mesmo o isolamento geográfico, aumentando os custos com o transporte de pequenos volumes, contribuiu para a trajetória independente e verticalizada da empresa I. Hoje, faz desta circunstância, originalmente não intencionada, uma vantagem competitiva, pois configurou uma estrutura de custos que apresenta pouca sensibilidade às variações: mix de produto, processo, tamanho de lotes etc. Assim, a EA não se aplica como estratégia para a redução de custos, aumento da eficiência e maior competitividade.

Como subproduto da pesquisa emergiu o critério utilizado pelas empresas para se autodenominarem terceiras, diferenciando-se das subcontratadas ${ }^{(9)}$; assim, consideram-se terceiras as empresas que:

· são dependentes de um ou, no máximo, dois ou três outros clientes;

- têm o seu faturamento concentrado em produtos ou em processos aplicados sobre produtos, que só possuem valor reconhecido (utilidade) pelos seus clientes. Em outras palavras, equivale a dizer que um terceiro não possui uma linha (projeto) própria de produtos, sobre a qual tenha a liberdade de produzir, ofertar e negociar com outros clientes as condições que lhe forem da melhor conveniência.

· não dispõem da função comercial, uma vez que:

- seu cliente ocupa toda a sua capacidade produtiva;

- sua competência técnica (pessoas, máquinas, equipamentos, tecnologia etc) é restrita aos produtos/processos aplicados aos clientes, dos quais recebem os projetos, as especificações e, por vezes, os insumos e até mesmo as máquinas e ferramentas utilizadas na tranformação industrial;

- dispõem de reduzidos graus de liberdade em face dos diversos aspectos da sua gestão, em especial aqueles relativos à sua programação e controle da produção, pois o objetivo declarado ou não da empresa contratante é possuir na terceira uma linha complementar de produção, capaz de produzir e entregar justin-time nas suas linhas internas, como se aquela fosse uma extensão destas. De fato, a contratante identifica na contratada uma extensão natural da sua personalidade jurídica (das suas instalações industriais), para onde transfere e mantém estoques de matéria-prima e produtos acabados, assim como ativos já obsoletos, tanto do ponto de vista tecnológico quanto contábeis (depreciados);

- os pedidos de recompra dos mesmos produtos são automaticamente aceitos, sem negociações, reproduzindo as condições anteriores (do último pedido), independentemente dos reajustes ocorridos que alteram sobremodo as suas (dos terceiros) estruturas de custos, a exemplo dos aluguéis, salários (horas extras, remuneração diferenciada aos domingos e feriados), energia, combustível etc; 
- o fluxo de materiais/produtos, em que pese a importância, crítica para os dois lados, não é precedido da documentação habitual (orçamentos, ordens de serviço/de compra etc) o que facilita cancelamentos e alterações de última hora. $\mathrm{O}$ fluxo de materiais se verifica tão somente ao amparo da documentação fiscal, sendo o contrato e o distrato verbais e;

- habitualmente, conhecem e atuam, tecnicamente, apenas sobre uma etapa do processo produtivo do cliente ${ }^{(10)}$.

Ademais, verifica-se que um terceiro:

- normalmente possui instalações próximas às do seu cliente;

- divide com a família (envolvendo cônjuge, filhos, irmãos, cunhados etc) todas as rotinas do negócio;

- no início das atividades, a amizade direta (ou indireta, através de parentes) com o titular da empresa-cliente foi decisiva para a constituição da firma e, deste,

- recebeu apoio de toda ordem: financeiro, técnico, cessão de máquinas em regime de comodato, aval/fiança, incentivo, e;

- teve assegurado um mercado para os seus produtos/serviços.

Decorre dessas circunstâncias uma forma de relacionamento em que os aspectos pessoais se confundem com os profissionais; não raro, os sentimentos de submissão, dívida de gratidão e compromissos morais, da parte do terceiro para com o contratante, prevalecem sobre os critérios técnicos. Chama-se a atenção, também, para o fato de que as circunstâncias parecem determinantes para explicar a sobrevida média superior destas empresas, uma vez que as dificuldades de ordem administrativa e mercadológicas (identificação e dimensionamento da clientela, precificação, promoções, publicidade, distribuição, entre outras) são responsáveis pelo elevado índice de mortalidade entre as pequenas e médias empresas nascentes.

Contrariamente, um fornecedor tradicional (não-terceiro) apresentaria: uma carteira com vários clientes, ofertaria uma linha diversificada de produtos/serviços, desenvolveria as funções de pesquisa, projeto, comercial e cada negócio (com$\mathrm{pra} / \mathrm{venda}$ ) seria submetido a uma análise independente e criteriosa: preço, qualidade, prazo de entrega e condições de pagamento, entre outras variáveis, seriam objeto de árdua negociação. Em contrapartida, o preço da liberdade é o maior risco. 


\section{Consideraçóes Finals}

A abordagem da racionalidade limitada, de Simon (1979), sem dúvida, é a consideração mais abrangente e universal sobre a externalização de atividades, explicando tanto os comportamentos individuais quanto os das organizações.

Da teoria dos custos de transação pode-se dizer, não sem uma certa simplificação, que chama ao administrador a capacidade de decidir e modificar, de dentro para fora, mediante critérios, os rumos da firma, até então, um conjunto de recursos sob as forças dominantes do mercado. Ainda, externalizar (ou não) é o resultado de um processo decisório que contempla tanto variáveis objetivas (condições internas versus externas de preço, capacidade produtiva, qualidade etc), quanto subjetivas, a exemplo do risco implícito desta decisão, que, sem prejuízo de outros aspectos, deve predominar sobre o custo do vazamento de segredos industriais, da ocorrência de uma sabotagem, da perda de controle sobre as condições de negociação etc.

Definir uma core competence e sobre ela focalizar as ações gerenciais, a priori, pode não ser uma recomendação generalizada, independentemente das circunstâncias do entorno, da tecnologia, do porte da empresa, das relações de força que mantêm com seus clientes e fornecedores, do dinamismo tecnológico no seu setor de atuação, da qualificação da sua mão-de-obra etc. Segundo alguns relatos, mesmo tendo logrado êxito na EA com vistas a focalizar as ações sobre os fatores críticos de sucesso, a exigência por maior produtividade conduziu empresas ao caminho inverso, por exemplo, na automação das linhas produtivas. Uma primeira explicação para este comportamento parece residir nas máquinas $\mathrm{CNC}$, presentes na maioria dos projetos de modernização:

- Por um lado, proporcionam acréscimo significativo de volumes por hora/máquina, melhor qualidade de conformidade com o projeto, menor índice de perdas, reduzidíssimos tempos de set-up, realizam múltiplas funções e possibilitam integração com outros sistemas.

- Por outro, exigem que uma grande soma de recursos sejam imobilizados, tanto para a aquisição das máquinas, quanto para a preparação do ambiente de trabalho, e requerem profissionais mais qualificados (maiores salários) para a operação.

Nessas condições, para se tornar viável economicamente, o projeto requer grandes volumes, levando à reinternalização de processos e/ou à diversificação da linha de produtos. 
Há casos também que, seguindo uma das tendências da indústria automobilística, a que aponta a transformação das empresas produtoras de peças e componentes em fornecedoras de sistemas, algumas empresas reinternalizaram atividades agora críticas e indispensáveis ao novo produto.

Por um lado, as cadeias produtivas localizadas constituíram (constituem) exemplos de trajetórias exitosas, a partir de estruturas surgidas em resposta às adversidades histórica e geograficamente pontuais; por outro, para o sucesso, as empresas não podem prescindir, só pelo fato de integrarem a cadeia, da análise criteriosa (objetiva e subjetivamente) de todas as condições que afetam a decisão de fazer e/ ou comprar.

Por fim, no que tange às práticas de cooperação interfirmas, também não há elementos que permitam afirmar ser esta uma condição sine qua non para o aumento da produtividade/competitividade e tampouco que os indicadores desta cooperação (troca de informações, repetição de compras etc) caracterizem a forma de relacionamento denominada de parceria. Para que possa ser caracterizada a cooperação, elemento fundamental da relação entre parceiros, devem prevalecer atitudes e ações que a ambas as partes beneficie (relações tipo ganha-ganha); entretanto o que se verifica no campo é que, poucas vezes, conforme já destacado por Pinheiro (1995), a cooperação se reveste da bilateralidade, prevalecendo as relações tipo ganha-perde. Curiosamente, em que pese que a literatura, de modo geral, aponte o Japão como o país onde as relações de parceria (tipo ganha-ganha) tenham alcançado um dos mais altos níveis de maturidade, Silva (1997), em ensaio recente publicado na revista Exame, destaca que:
“[...] idéias como diálogo e contemporização não fazem parte da cultura japonesa. Mata-se e morre-se antes de qualquer tentativa de entendimento. De certa forma, o estilo japonês de fazer negócios ainda é muito marcado por esse espírito. O modelo ganha-ganha de negociação não faz o menor sentido entre os japoneses. Não interessa se o ganha-ganha, ao assegurar a satisfação de ambas as partes, gera resultados mais perenes e parceiros mais leais. Para o japonês, o ganho de um dos lados está freqüentemente associado à perda do outro. Ou seja, quem tem o poder está bem colocado na cadeia hierárquica e usa isso para obter todos os privilégios possíveis. Quem está em posição inferior obedece e amarga perdas".

$\mathrm{Na}$ amostra pesquisada, os depoimentos, na sua maioria, foram contundentes no sentido de configurar um relacionamento tenso, pautado na incerteza e contemplando, majoritariamente, os interesses individuais. Ademais, além dos níveis 
destacados por Carleial (1996), a pesquisa sugere a existência de diferentes tipos de cooperação, determinados, em certa medida, pelo tipo de relacionamento dominante interfirmas. Assim:

- Entre um cliente e um fornecedor tradicional,

- predomina o tipo de cooperação profissional, realizada através de projetos, com objetivos, metas, avaliação e atribuição de responsabilidades. O fluxo de informações e o apoio gerencial e técnico do cliente para o fornecedor visam a assegurar a qualidade e manter a rastreabilidade dos seus produtos. A cooperação resulta também da necessidade que o cliente possui de estar próximo ao seu fornecedor, visitando-o (avaliando-o) com freqüência; assim comprometeu-se para obter a certificação. Pode-se, entretanto, falar de ganho para os dois lados, pois o fornecedor absorve o conhecimento técnico e o utiliza para toda a sua carteira de produtos e clientes; assim, ambos tornam-se mais produtivos e competitivos. Os fornecedores dos itens de maior criticidade (técnica, valor etc), tão somente por esta razão, são denominados de parceiros, constituindo esta talvez uma estratégia da empresa-cliente com vistas a diminuir os riscos de interrupção de suprimento.

- Entre um cliente e um fornecedor terceiro,

- predomina um tipo de cooperação em que os laços pessoais são mais fortes que os determinantes técnicos. A cooperação é voluntarista, pessoal, sem projetos, objetivos ou metas para serem avaliadas. A cooperação, como atitude de iniciativa da empresa-mãe (cliente), limita-se ao início das atividades da empresafornecedora (terceirizada). A partir de então, o que a grande empresa denomina como colaboração são, de fato, intervenções para auxiliar na solução de problemas técnicos, cujo alcance esteja acima das possibilidades do fornecedor-terceiro. Nesses casos, o que se verifica é um relacionamento unilateral, sendo por vezes difícil a identificação e a quantificação das vantagens acumuladas pelo terceiro. Há casos até em que a relação se aproxima do tipo dominação-subordinação; enquanto o segundo sobrevive, o primeiro acumula competitividade.

Não se pode, portanto, nem afirmar que a externalização de atividades seja prática universalmente necessária, inexorável e muito menos suficiente para aumentar a produtividade e a competitividade das organizações; tampouco se percebe, nas relações empresa-cliente/empresa-terceirizada, um novo padrão ético de relacionamento interfirmas pautado na parceria através da cooperação.

Por fim, embora o trabalho tenha sido realizado sobre o setor de autopeças, acredita-se que as condições aí encontradas se verificariam em outros setores. 


\section{NOTAS}

${ }^{1}$ Trata-se da pesquisa executada pela equipe do Centro de Estudos, Educação e Sociedade (CEDES) da Universidade de Campinas, que teve por objetivo analisar alguns aspectos relativos ao processo de reestruturação produtiva em curso no país, mais especificamente, o do relacionamento interfirmas e o da qualificação da mão-de-obra. Contando com recursos do CNPq e da FINEP, a pesquisa teve atividades distribuídas e realizadas em várias unidades da federação. No Rio Grande do Sul , sob a coordenação do Prof. Roberto L. Ruas (PPGA/UFRGS), analisou os aspectos mencionados, nos setores de autopeças e calçadista.

2 Posteriormente revisada e denominada de neoclássica.

${ }^{3}$ Chief executive office.

${ }^{4}$ Conceito utilizado para designar um conjunto de empresas, individualmente especializadas, que mantém relações de suprimentos (peças, componentes, serviços etc) no âmbito de um mesmo setor (subsetor) econômico.

5 As sete ferramentas da qualidade, entre outras.

${ }^{6}$ Troca rápida de ferramentas, manutenção produtiva total, produção em pequenos lotes, kanban, sincronização da linha de produção, organização celular, poka-yoke, entre outras.

${ }^{7}$ A externalização de atividades é uma prática tão antiga quanto o capitalismo; todavia adquire feições de nova porque, ao mesmo tempo que vem rompendo com o predomínio do discurso da eficiência localizada e individual, apresenta, também, tendências para se consolidar como hegemônica. Alguns chegam a atribuir a esta mudança, uma dimensão paradigmática.

${ }^{8}$ Todas as informações aqui citadas foram obtidas em entrevistas com os dirigentes das respectivas empresas.

${ }^{9}$ Cabe lembrar que todas as empresas pesquisadas, ou contratam, ou são contratadas para a realização de atividades direta ou indiretamente relacionadas a produtos/processos aplicados à indústria de autopeças. Assim, ao denominar-se como um terceiro, a empresa, de fato, está se distinguindo como um tipo especial de fornecedora.

${ }^{10}$ Os terceiros que dominam e realizam todo o processo produtivo do seu cliente (entregam o produto completo), em certa medida reproduzindo as condições deste, recebem a denominação de faccionistas; entretanto a diferença entre terceiros e faccionistas não se limita apenas a este aspecto.

\section{ReferénCias Bibliográficas}

ABREU, A. R. DE P.;

SORJ, B.

Subcontratação e trabalho a domicílio : a influência do gênero.
In: MARTINS, H. H. T. DE S.; RAMALHO, J. R. (Orgs.). Terceirização : diversidade e negociação no mundo do trabalho. São Paulo : Hucitec/CEDI, 1994. 
BASAY, M. V.

La micro y mediana empresa peruana, camino a la globalización - caso : sociedad de consorcios de exportación de Gamarra. Trabalho apresentado ao Congresso Latinoamericano de Administración, Santiago, Chile, 1996.

BRASIL, H. G.

A empresa e a estratégia da terceirização. Revista de Administração de Empresas, v. 33, n. 2, p. 06-11, mar./abr. 1993.

BRUSCO, S.

The idea of the industrial district : its genesis. In: PYKE, F.; BECATTINI, G.; SENGENBERGER, W. (Orgs.). Industrial districts and interfirm co-operation in Italy. Geneva : International Labour Organisation, 1990.

\section{CADERNOS CEDOPE.}

Apresentação. São Leopoldo : Unisinos, v. II, n. 9, 1993.

CARLEIAL, L. M. DA F.

Reestruturação industrial, relação entre firmas e mercado de trabalho : as evidências na indústria eletro-eletrônica na região metropolitana de Curitiba. Trabalho apresentado ao Seminário Quais os Reais Efeitos da Reestruturação Produtiva sobre o
Mercado de Trabalho? Curitiba, 1996.

CORRÊA, H. L.;

GIANESI, I. G. N. Just in time, MRP II e OPT : um enfoque estratégico. 2. ed. São Paulo : Atlas, 1993.

COURLET, C.

Novas dinâmicas de desenvolvimento e sistemas industriais localizados (SIL). Ensaios FEE, v. 14, n. 1, p. 09-25, 1993.

CUNHA, A. M. DA.

Forma de organização dos mercados em rede de produtores e fornecedores. Revisão bibliográfica, 1996.

DOSI, G. et al (Orgs.).

Technical change and economy theory. London : Pinter Publishers, 1988.

DUTRA, C. A. F.;

CASTILHOS, D.; BORBA, L. A. M.

Cooperativas de trabalho e a terceirização. Cadernos CEDOPE, v. II, n. 9, p. 04-08, 1993.

FREEMAN, C.

The national system of innovation in historical perspective. Cambridge Journal of Economics, p. 05-24, 1995. 
HAMEL, G.;

PRAHALAD, C. K.

Competindo pelo futuro : estratégias inovadoras para obter $\mathrm{o}$ controle do seu setor e criar os mercados de amanhã. Rio de Janeiro : Campus, 1995.

HENKIN, H.

Fundamentos teóricos da subcontratação industrial : formulações à luz da teoria dos custos de transações. Porto Alegre, 1995. (mimeo).

ISHIKAWA, K.

Controle de qualidade total : à maneira japonesa. Rio de Janeiro : Campus, 1993.

\section{KRUGLIANSKAS, I.}

Tornando a pequena e média empresa competitiva : como inovar e sobreviver em mercados globalizados. São Paulo : IEGE, 1996.

LEITE, M. DE P.;

POSTHUMA, A. C.

Reestruturação produtiva e qualificação. Projeto CEDES/ FINEP/CNPQ, 1995.

LINDBLOM, C. E.

The science of muddling through.

Public Administration Review, p. 79-88, 1959.

MONDEN, Y.

Sistema Toyota de produção.
São Paulo : IMAM, 1984.

MOTTA, P. R.

Gestão contemporânea : a ciência e a arte de ser dirigente. 5. ed. Rio de Janeiro : Record, 1995.

OHNO, T.

Toyota productiom system : beyond large-scale production.Cambridge: Productivity Press, 1988.

PETERS, T.;

WATERMAN, R.

Vencendo a crise. Rio de Janeiro : Harper \& Row, 1983.

PINHEIRO, I. A.

O que vem a ser parceria? Análise de algumas experiências verificadas no RS a partir do TQC/JIT. Porto Alegre, 1995. Dissertação (Mestrado em Administração) - Programa de Pós-Graduação em Administração, Universidade Federal do Rio Grande do Sul.

PYKE, F.;

SENGENBERGER, $\mathrm{W}$.

Introduction. In: PYKE, F.; B E C A T T I N I , G .; SENGENBERGER, W. (Orgs.). Industrial districts and interfirm co-operation in Italy. Geneva : International Labour Organisation, 1990. 
SHINGO, S.

O sistema Toyota de produção do ponto de vista da engenharia de produção. 2. ed. Porto Alegre : Bookman, 1996.

SILVA, A.

Decifra meu sorriso ou te devoro. Exame, São Paulo, 12 mar. 1997, p. $82-85$.

SIMON, H. A.

A rational decision making in business organizations. The American Economic Review, p. 493-513, Sept. 1979.

XAVIER, E. P.

Círculos de controle de qualidade : um método gerencial renovador porém... Curitiba : Centro de Produtividade do Paraná, 1983.

WILLIAMSON, O. E.

Strategizing, economizing, and economic organization. Strategic Management Journal, v. 12, p. 75-94, 1991.

WILLIAMSON, O. E.;

WINTER, S. G. (Eds.).

The nature of the firm - origins, evolution, and development. New York : Oxford University Press, 1993.

WOMACK, J. P. et al.

A máquina que mudou o mundo. 3. ed. Rio de Janeiro : Campus, 1992.

\section{ZYLBERSZTAJN, D.}

Entre o mercado e a hierarquia : análise de casos de quebra contratual no agrobusiness. In: XX ENCONTRO ANUAL DA ANPAD (1996: Angra dos Reis). Anais... Rio de Janeiro : ANPAD, 1996. 